\title{
CLINICAL AND HEALTH PSYCHOLOGY
}

\section{The development of affective behavioral complexes: a level-based model}

\author{
Marina K. Bardyshevskaya \\ Lomonosov Moscow State University, Moscow, Russia
}

\begin{abstract}
The author discusses sources for, problems in, and ways of forming a hierarchical model of the development of whole affective behavioral complexes, not just mechanisms of emotional regulation, as was done in the original level-based model elaborated by Victor Lebedinsky. The author describes specific traits of affective behavioral complexes and types of links between them on different levels. Primitive affective behavioral complexes, either isolated or rigidly linked, dominate on the lower three levels. On the fourth level attachment behavior plays a "star" role, mediating and regulating all vital behaviors. On the fifth level symbolic activity permanently rebuilds the experience obtained on the lower levels. The author discusses links between affective behavioral complexes and nuclear personality formations.
\end{abstract}

Keywords: development, affective behavioral complexes, regulation, attachment, symbolic activity

The level-based model of emotional regulation was developed on the basis of research on the psychic development of children with early child autism (Lebedinsky, Nikolskaya, Bayenskaya, \& Libling, 1990).* The theoretical bases of the model were the ideas about a tier organization of living systems in general biology, the clinical-psychiatric concepts of nervous and psychic reaction to harm (Kovalev, 1985; Sukhareva, 1959), the theory of child stage-by-stage psychic development (Vallon, 1967), and the ethological models of a level-based organization of human and animal behavior (Hinde, 1975; Tinbergen \& Tinbergen, 1983).

* The words basal emotion and affect, emotional and affective are used here as synonymous to denote any emotional phenomenon with a focus on its psychophysiological and behavioral basis. Alhough the term emotional regulation has not been clearly defined by V. V. Lebedinsky, it is related to the emotional regulation of psychic tonus, of behavior, and of certain types of emotions that are regulated by other emotions. 
The underlying notion has become N. A. Bernshtein's idea of levels as new ways of coordinating different behaviors, as new stages in the structural-dynamic changes of a living self-regulating system; these levels provide for the achievement of meaningful behavior. The original version of the model (Lebedinsky et al., 1990) dealt with a few of Bernshtein's basic ideas: "heterochronism"; a hierarchy of the essential (major) level and the background levels; a hierarchy of the behavior-regulation mechanisms; the mechanisms of disorders, such as the loss of control of upper mechanisms over lower ones (i.e., hyperkinesis, synkinesia, elementary expressive and protective movements); the disproportion between levels; the aggravation of symptoms from inconsistency of a behavior to its loss (Bernshtein, 1990).

Lebedinsky and colleagues (1990) originally analyzed four basal levels of emotional regulation: emotional regulation of field reaction, of stereotypes, of expansion, and of emotional control. Lebedinsky (2003) metaphorically compared these levels to geological layers, each of which has a structure and function of its own, but he pointed out two brain layers - the subcortical and cortical areas - thus contrasting the early-evolving basal emotions with their largely toning-up function and the intellect-dominating development processes.

The level-based model of emotional regulation is currently being developed in two ways: (1) as a largely philosophical and cultural analysis; (2) as an analysis of the level-based organization of behavior and of the corresponding emotional states and symbolic activities and their regulation.

Nikolskaya's (2000) level-based model of the affective organization of consciousness and behavior focuses on the culturally predetermined development of the affective sphere, the generation of new meanings, and the evolution of a new type of experiences and environmental contacts. She describes metaphorically the mechanisms of affective development ("swing," "adventure"). A child's affective impulses are contrasted with the culture, with the system of social conventions, and with attachment; they are evaluated from "the future," from the height of human spiritual growth. She uses the method of culture studies, the analysis of anthropological literature and fiction. This shift of analytical focus is probably due to the methodological difficulties in researching basal emotions beyond the early childhood period and in cases of severe emotional disorders.

\section{The original five-level system for the assessment of emotional regulation}

Having studied models of the hierarchy of symbolic activity, which includes elementary forms closely related to affect and behavior (Segal, 1986), Lebedinsky and Bardyshevskaya (2002) added the highest level to the system of basal emotional regulation. It corresponds to the fifth level in Bernshtein's model. In order to understand the development of symbolic activity, the following should be studied: (1) ways of transforming emotional states into emotional experience (what is symbolized, remembered, or thrown away; how an experience is connected to a symbol: on the basis of what features a symbol is selected and whether and how does a child mark the difference between the symbol and the symbolized); (2) the organization of emotional experience (according to what categories is it generalized and differentiated); (3) encrypting part of an emotional experience into the core structures of 
a child's personality (what am I). In addition, mechanisms of attachment behavior were added to the model. These mechanisms play an important role in regulating the basic behaviors and emotional states of a child, especially acute and intensive ones. This addition made it possible to take into account the hierarchical organization of the level of affective communication and to study the interaction between the two systems of emotional regulation-a child's and a parent's-whereas in the original model a parent's emotional regulation was by default viewed as a stable, nonpathogenic characteristic, and breakdowns were seen as a lack of balance in the child's system of emotional regulation.

Bardyshevskaya and Lebedinsky (2003) developed a procedure for the assessment of emotional regulation based on the five-level model. It involves ethological and psychoanalytical observations of children's behavior and emotional states in the clinical and in the natural environment as well as interviews with their parents and other experts working with them. An observer determines and qualifies emotional disturbances caused by insufficiency or loss of the mechanisms of emotional regulation on each level. A profile of emotional development is identified through qualitative and quantitative analysis of unstable, distorted, impaired, fixed, and missing affective phenomena and the links between them. The results of longitudinal studies of children's development (Bardyshevskaya, 2010; Bardyshevskaya \& Trenina, 2008; Klimas, 2008; Mikhayilova, 2004) demonstrate that affective phenomena similar to pathological ones often have no prognostic value, whereas variants of dynamics, connections, and successions of affective manifestations are important for diagnosis, prognosis, and psychotherapy.

This level-based model of emotional regulation has not been used widely, possibly for the following reasons: (1) the vagueness of the original definitions; (2) the insufficiency of the clinical sample, which included only children with early child autism and early child schizophrenia; (3) the methodological complexity and the resource consumption of the assessment; (4) the fact that the focus is primarily on safety mechanisms for regulating nonreversible affective ejections; (5) the lack of specific differential diagnostic criteria of the norm, delay, distortion, and impairment for children of different ages and with emotional and personality peculiarities.

\section{A new level-based model of the development of affective behavioral complexes}

The current model is focused on the level-based development of elementary affective behavioral complexes and their placement within the core personality structures at different developmental stages. ${ }^{*}$ The model enhances the ideas of Bernshtein and Lebedinsky and the preconceptions of early holistic forms of affective communication, the preconception of attachment and emotional ties as a basis for the development of other behaviors throughout a lifetime (Ainsworth, 1991; Bowlby, 2004), and the preconception of the early development of elementary forms of symbolic activity and their hierarchic organization (Segal, 1986).

An elementary affective behavioral complex includes an ethologically determined behavior (sleeping/wakefulness, self-preservation, eating, excretion, terri-

* All the examples below are the author's observations. 
toriality, nonverbal communication, attachment, exploration, play, aggression, and sex) and the inclinations, emotions, and symbolic activity related to this behavior.

Elementary affective behavioral complexes dominate in the psychic activity of children under 3 years. Further on, especially within periods of fast or significant changes, strengthening these complexes is important in order to support what Vallon (1967) called "a special focus on finding the most lively part of oneself." My research shows that elements of early affective behavioral complexes preserve their regulatory function throughout childhood at times of stress, illness, and tiredness even in the normal population.

Basal emotions (protopathic sensitivity, disgust, fear, displeasure, enjoyment, joy, anger, interest) are originally merged with motor functions and somatovegetative reactions and appear within the framework of affective behavioral complexes. Their basic individual specific characteristics include: intensity, sign, cyclic recurrence, expression, and typical interactions with other emotions.

Basal emotional regulation is a system of basal emotions and affective behavioral mechanisms identifying, modulating, and ordering these emotions: approach and avoidance; contraction, expansion, or shifting of attention; behavior (displaced or redirected activity) and affective memory; the conditioning, inhibiting, weakening, or strengthening of an emotional state through clashes with other emotions; adoption of the emotional state of another person; imitation of another's emotional expression; symbolization; role playing; use of basic rules (taking turns in interaction, rhythmical coordination of eye and voice contact). Regulation takes place at different levels of an individual's self-organization (both employing and not employing conscious and cognitive processes) in order to support and strengthen the feeling of the lively in oneself, the wholeness of oneself, by providing optimal psychic tonus, readiness for and adaptation to affective loads, and the ability to save oneself from nervous exhaustion. The goal of preventing excessive emotional burdens is important but not essential.

Early behavioral complexes children involuntarily use to regulate their emotional state are the following: (1) escape (passive or active avoidance); (2) temporary restoration of previous rhythms and patterns of eating, drinking, excretion, sleeping-wakefulness, and tonifying or relaxing movements; (3) expansive movements (general agitation, screaming, impulsive movements such as aggression, capture of territory or objects); (4) attachment patterns (grabbing, clinging, searching behavior) and intensive expressive movements (crying, grimaces); (5) reproduction of a pattern if the desired object is missing (displaced or redirected activity).

Core personality structures that remain stable during periods of fast changes are the following: a feeling of oneself as a living source of psychic activity, a feeling of oneself as a carrier of individual emotional experience different from other people's experiences, an individual style of affective life (preferences in the choice to retain and strategies for retaining a desired experience, special behavior if the experience is lost, strategies for eliminating a nondesired experience), and early personality identifications.

Findings of research in maternal deprivation are important for understanding level-based affective organization (Harlow, Harlow, \& Suomi, 2002). The longer and harsher early maternal deprivation is, the more overt is the basal layer of emotions and behaviors. The most basic emotions and behaviors are strong fear and passive 
avoidance, then anxiety and a primitive tactile contact like grabbing or clinging in order to calm down; further on come anger and aggression, first without considering the state of the other person, and later a differentiated aggression. The more successful compensation is, the more complex the coordination between different behaviors appears (Bardyshevskaya, 1995).

The notion of level is close to the notion of postural tonic position in that it enables children to express their internal state and at the same time to imitate external impressions (Vallon, 1967). Ideas underlying our concept of a level of symbolic regulations are those of Segal (1986), who proposed the existence of a hierarchy of forms of symbolic activity.

The level of development of an affective behavioral complex in my model includes: (1) special affective loads that trigger (regulate) the complex; (2) characteristics of basal emotions most sensitive to these affective loads; (3) stable cycles (successions, "merry-go-rounds") of emotions; (4) types and the repertoire of behaviors; (5) types of symbolic activity: characteristics of the emotional experience being acquired, categories for the generalization and differentiation of experience, ways affective memory works; (6) ways of experiencing oneself as a living center of activity, forms for showing oneself and for escape ("hiding" oneself); (7) ways to prevent affective breakdowns; (8) types of links between elements of the same affective behavioral complex: isolated, rigid, "star-shaped," hierarchic (Lebedinsky, 2003; Malinovskyi, 2000); (9) types of links between one complex and other complexes.

Affective loads of the first level, evaluations of the intensity of environmental effects, cause phylogenetically old, undifferentiated (protopathic) emotions, sensibilized (perceptible because of past experience) emotions, as well as behavioral manifestations closely related to these loads: approach/avoidance, allowing the choice of optimal load intensity. A special load is the intensity of characteristics important for adaptation, such as brightness, color, shape, size, movement, pain. Perception dominates in an affective behavioral complex-in a modality most finely adjusted for finding harmonious impressions, often accompanied by motor, behavioral inactivity. An example of a behavior observed mainly at the first level is territoriality (being snug in a mother's arms, searching for an optimal place in a room). Impressions are acquired if they are "nice"-that is, if they possess features that are optimal in terms of biological aesthetics. ${ }^{*}$ Disharmonious effects are experienced as an interference, a threat, and are ignored. The affective memory works by recognizing and storing examples of the "nice" and the "ugly", the harmonious and the unharmonious (sharp, sudden) changes in the intensity of effects, the matches between load intensity and response intensity.

In order to prevent affective breakdowns in a child whose self-expression is weak, who shows no self-manifestations, is shy, is lost in perceptions, does not feel time go by, basic forms of defense from overexcitation are needed: escape, sleep, psychophysiological anesthesia, the freezing of activity, closing of eyes and ears, turning away, looking away and defocusing (when two eyes are looking in different directions at the same time), or fixing eyes on a beautiful/simple shape.

* The benchmark for "nice" in this context is, for example, a set of impressions aroused by the mother-her touch, warmth, smell, and the color, smoothness, and softness of her skin. 
At the second level, the level of affective stereotypes, the feature of a basal emotion most susceptible to affective loads is the sign of the basal emotion. This sign can be merged positive emotions (enjoyment plus joy) or negative ones (displeasure, anger, fear, disgust) as well as more differentiated emotions. At this level behavior is enacted through the mechanism of inclinations, which are fixed affective behavioral syncretic complexes characterized by an inalterable succession of actions and stereotypical dynamics of affect. An example of a baby's supervaluable behavior is sucking at the breast, which requires a special body pose and other conditions. Hysterical reactions, autoaggression, and similar behaviors are also enacted according to a rigid pattern.

The loss of any element of the complex is experienced as a disaster. Emotional outbursts have a rigid cyclic organization and are hard to regulate externally. If a whole affective behavioral complex is lost (for instance, when a mother stops breastfeeding), the child continues for a long time certain elements, fragments, of these complexes, like sucking a thumb, fiddling with the mother's or his or her own hair.

Connections between various affective behavioral complexes are also rigid. Normally these connections are positive and support a positive tonus of activity. If the environment is very changeable or if a few affective behavioral complexes break down, children's viability decreases; they become vulnerable to somatic disease and there are failures of vital behaviors (eating, sleeping, for example). Any negative experience becomes easily fixed. As a result the following affective behavioral event cancels or negatively reinforces the preceding one: the child eats and vomits, wakes up and cries.

Recurrent affective behavior at this level is easy to symbolize and is distinctly divided into "good" and "bad," with the result often depending on the first affective impression. Affective behavioral stereotypes are partly encrypted as symbols, and affective images remain closely connected with bodily experiences and movements. Children 2-3 years old have psychologically clear and culturally mediated images; for example, playing with the mother's hair is transformed into weaving a carpet, clinging to her is like climbing a ship's mast. Children with developmental defects are characterized by the fixing of the primitive perception of objects and situations on the basis of links existing at the bodily level: equalizing different parts of the body (hand, breast), equalizing substances (milk, blood, water), equalizing objects (finger, paint brush). For example, a boy 9 years old took autoaggressive actions like biting his hands and wrists; these actions were a transformed attack on the mother's breast, which replaced hands and wrists in his drawings of human figures.

One mode of the working of affective memory is imprinting. A feeling of the lively in oneself is supported by the multiple reproduction of behavioral cycles, which is strengthened when one recognizes one's own experience and is weakened when one encounters others' experiences. Self-expression is realized through the individualization of an affective behavioral complex, its rhythm and style, preferences, links with other behaviors. Thus, in one case a child 4 years old received prolonged breastfeeding, which was accompanied by a special symbolic game with the mother's body that ceased after breastfeeding was stopped. 
At the third level, the level of affective expansion, affective loads trigger polar emotions (fear and interest, pleasure and anger). The loads are remoteness, height, depth, darkness, novelty, complexity and material indefiniteness, vagueness of shape, borders, confusion (a mix of lively and nonlively features, for example, in the same object), failure, signs of domination or threat in another's behavior. At this level children experience themselves as a source of psychic activity and competence. New achievements, new abilities, the expansion of personal space are accompanied by a favorable emotional background, which decreases a child's feeling of danger or "edge." Such a state can be preceded by a period of low spirits, when a pensive mood, inhibition, and stereotypically safe activities predominate and the child is hypersensitive to any loads challenging the borders of self.

The emotional experience at this level enables children to feel the changes in their personality that are maintaining their personal identity. The mode of working of affective memory is the selective imprinting of the experience of one's own emotional strength, resilience, competence. The child calls himself/herself "a little one" or "a big one," claiming exactly the age that matches his/her actual experience of opportunities or limits.

The tonifying effect of a child's acting out a new behavior is usually a short-term one. If the behavior does not die out within a few months or years, it is used as a stereotype. As affective behavioral complexes are rigidly targeted at tonifying by means of external expansion, they can easily replace each other-that is, connections between them are flexible and not strictly hierarchic. Children under 7 exhibit short-term, "star-shaped" behavior (Malinovskyi, 2000), which competes with attachment behavior; star-shaped behavior is exploratory, play behavior (competing for objects, territory, power; "quasi-aggression"). When attachment behavior loses its leading position in the hierarchy, children experiment with food or their bodies for self-affirmation.

Pathology is marked by the fact that affective behavioral complexes are irregularly developed at this level, with some elements inhibited and others exaggerated. For instance, in one case a 5-year-old child could hold his breath for a long time underwater but was terrified of going down the stairs.

An affective breakdown caused by failure permits the prevention of exploratory action (observing the situation in order to understand the allocation of forces, making preliminary estimates of "activity costs"), the "holding back" of expansive action until the best conditions for its implementation set in, the redirection of activity, the symbolic acting out of overcoming danger, and the toning up of the child's independent activity by an adult. The traditional vacillation is between the positive pole of emotional states (at the stage of costs) and the negative pole (at the stage of energy saving).

At the fourth level, that of basal affective communication, a special load is one's own or another person's expression of affect (gaze, mimicry, poses, gestures, gait, intonation, smells, somatovegetative changes). Affective behavioral complexes are various and hierarchic within the framework of attachment behavior (fear of a stranger, protest against separation, greetings, socializing play, and so forth). At this level the dynamics of affect depend to a greater extent than at other levels on the dynamics of affect of the person with whom the child communicates. 
The earliest mechanisms strengthening the feeling of the lively in oneself are adopting the emotional state of another person and imitating it; ${ }^{*}$ the later-emerging mechanisms contrast one's own behavior and emotional state with the behavior and state of another person. At this level people are differentiated on the criterion of "my own" - "another's." Also, one's own and another's emotional states are differentiated here; ${ }^{* *}$ the child adopts rules of emotional communication that can hardly be consciously regulated (for example, turn-taking in communication, coordination of nonverbal contacts, eye contact and speech, rotation of the direct expression of one's emotions and shyness).

Affective breakdowns like aggression and depression are due to overexcitation during a contact or to contact defects (distortion, insufficiency, interruption). Affective breakdowns can be prevented through anticipation of the dynamics and regulation of emotional contacts under pressure (avoiding eye contact, keeping silent, being alone), activation of previous attachment patterns (embraces, tactile contact), or change of partner.

Connections between affective behavioral complexes at the level of basal affective communication are determined by the domination of attachment behavior or social contact. Normally nonverbal communication is enriched when combined with play and other types of social behavior (exchange, for example). In the case of pathology, as the automation of emotional-contact rules is very complex and the costs of emotional contact are very high, the connections of social contact with other behaviors are negative. Thus a 2- or 3-year-old normal child can express himself/herself freely and show short-term embarrassment, shyness, or hesitation in turn-taking in communication. A child under 7 years old with slight distortions can undergo a period of steady contact avoidance. A child at any age with significant distortions can display autoaggression or self-punishment.

Periods when a child demonstrates his/her needs and controls the other's behavior (infects the other with his/her own mood, imposes a role, shows that he/ she requires care) alternate with periods when the child carefully chooses affective behavioral complexes that take into account the state of the other person. These periods are different depending, for example, on the number of people present and whether they are "one's own" or "strangers," their status, the child's tiredness and somatic condition. For example, in the child community of a childcare facility a child develops eating and sleeping patterns shared with other children, and they may differ greatly from the patterns at home. If attachment to parental figures dominates over attachment to mates, it leads to a certain regress to infantile behaviors; the

* Tuning in to the communication partner (regardless of whether that person is the mother or another infant), which is identified by the activity of "mirror neurons" or "sympathy" (Trevarthen, 2005, p. 67), is found in children very early, long before the behavioral pattern of "shared attention" has been formed (by the age of 9 months). Infants imitate adults" movements and display a change in heart beat half an hour after they are born (Trevarthen, 2005, p. 75).

** According to Simonov (1987), there are two systems of basal affect: the first is "for oneself," and the second is "for others"; in their basic forms both have the same substratum in the brain. Thus, the central gray substance is in charge of both one's own negative perceptions (temperature, tactility, sounds) and one's reactions to the negative emotional condition of the partner (p. 31). 
child enjoys feeling like "a little one." If rules of social contact dominate, it lessens the probability of affective conflict when a few types of competing behaviors are enacted.

At the fifth level, that of symbolic regulations, internal images of affective behavioral complexes (attachment, aggression, and so forth) are formed as well as their elements and the links between them. Also, the experience of the realization of these complexes and their changes is differentiated, generalized, and ordered. Recurrent emotional experience related to vital experiences like "beautiful-ugly," "living-dead," "one's own-somebody else's," "male-female," "young-old," and the like forms the core of a child's personality. Specific loads are inner conflict states when a few affective behavioral complexes are activated along with polar emotions connected with the same load and a few symbolic "casts" of the same emotional experience, each of them different in quality and level of generalization. ${ }^{*}$

The most elementary infant forms of symbolic activity are originally merged with behavior and affect and are spontaneous in a child's communication, explorations, and play. Archetypical games with indiscrete materials like water and sand, with balls, pieces of cloth, strings, objects combining hard and soft parts, and three-dimensional objects with inner space display an individual style related to the child's early experience. In his or her own individual way, every child connects the first, often unconscious or partly conscious, symbols, which refer to his or her own and the mother's body, parts of their bodies, body products, physiological processes.

For a child between 2 and 5 years of age many symbols are syncretic; in them individual, vivid schemes are merged with signs (Bernshtein, 1990, p. 137). Children play with toys suggested by the society and use them as a means for symbolizing their affective impulses and experiences; for this reason their functional significance is not stable and may differ from the acknowledged one.

The external expression of affect is reduced as long as it is affectively charged; lacking or conflicting elements of a behavioral affective complex are matched with symbols enabling the comprehension of behavior and its regulation. The process of searching for and selecting symbols (substitutional images) and the operations produced with them can be specific (an infant sucking on a small ball instead of a breast) as well as abstract (imagining combined with projecting an image into space; the "playing in a wall" of preschool children: a child looks at an empty wall and sees a cartoon projected there). Connecting and hierarchic coordination of symbols that significantly differ in structure and feasible operations are a special challenge. The more archaic a symbol or a complex of symbols fed by the same affect is, the more likely it is that the complex is isolated and the connections among its elements are rigid.

Integrating emotional experience and finding new ways of solving affective conflicts occur when the individual is in a pensive mood or a state of dreaminess or self-concentration (Trevarthen, 2005; Vallon, 1967). Whole patterns or fragments of affective behavioral complexes under which a certain experience was gained can

* For example, a child aged 4.5 years is asked to identify the movement (falling or rising) of a tune consisting of rising alternating minor and major chords. The child experiences a conflict as the sign of the emotion is not in line with the pitch of the sound. 
be revived. ${ }^{*}$ These patterns fulfill the functions of toning up, resting, providing a background that facilitates symbolic activity, having memories, and recalling fragments of experience for inner work with them.

Affective breakdowns happen when it is impossible to find an appropriate image to symbolize a conflicting or traumatic experience at basal levels and when there are big differences between a few images of the same affective behavioral complex, especially when they are actualized at the same time (confused) or when an individual emotional experience does not match cultural, conventional symbols or does not meet standard behavioral norms.

Symbolic images form a picture of their own and an image of the world that limit a person's ability to comprehend new connections. In the course of psychic development, periods of rapid formation of new connections (with mechanisms of the first, third, and fourth levels dominating on an elevated emotional background) alternate with periods when the already-formed connections are being fixed (with mechanisms of the second and partly the fourth and the fifth levels dominating on a neutral or a little lower emotional background).

This article provides a general outline of the level-based organization of affective behavioral complexes. No matter what developmental path affective behavioral complexes of different degrees of maturity take, they coexist. However, normally more primitive syncretic complexes (or their elements), in which affect is merged with behavior, serve as background complexes and are actualized when the person is tired, sick, or experiences emotional pressures or when the motivation of preserving a positive emotional experience is challenged by the motivation of psychophysiological survival. In pathological cases these syncretic complexes play the leading role.

A forthcoming article deals with the methods of studying affective behavioral complexes. It also presents lines of development, variations of breakdowns in development, and principles for their correction.

\section{References}

Ainsworth, M.D.S. (1991). Attachments and other affectional bonds across the life cycle. In C. M. Parkes, J. Stevenson-Hinde, \& P. Marris (Eds.), Attachment across the life cycle, 33-51. London, New York: Routledge.

Bardyshevskaya, M. K. (1995). Kompensatornyye formy povedeniya u deteyi vospityvayushchihsya $v$ usloviyakh detskogo doma [Compensatory forms of behavior in children reared in orphanages] (Unpublished doctoral thesis). Moscow: MSU.

Bardyshevskaya, M. K. (2010). Neverbal'naya communikatsiya u detey s narusheniyamy obshcheniya i emotsional'noy deprivatsiyeyi [Nonverbal communication in children with communication disorders and emotional deprivation]. Voprosy psihologii [Issues of psychology], 6, 33-42.

Bardyshevskaya, M. K., \& Lebedinsky, V. V. (2003). Diagnostika emotsional'nykh narusheniy u detey [Assessment of emotional disturbances in children]. Moscow: UMK Psychologiya.

* For example, when little children think of the mother's breast when she is not there, they make rhythmic grabbing movements with their hands in the direction that they fix with their eyes (they look at the imagined image). In the same situation children who already speak explain the meaning of their hand movement to their mother. 
Bardyshevskaya, M. K., \& Trenina, M. Yu. (2008). Osobennosty vlecheniy u detey s affectivnoy neustoichivost'yu [Peculiarities of inclinations in children with affective instability]. Voprosy psihologii [Issues of psychology], 3, 35-45.

Bernshtein, N. A. (1990). Physiologiya aktivnosty [Physiology of activity]. Moscow: Nauka.

Bowlby, J. (2004). Sozdaniya iI razrusheniye emotsional'nykh svyazey [Making and breaking emotional bonds]. Moscow: Academicheskyi proyect.

Harlow, G., Harlow, M., \& Suomi, S. (2002). Zamenitily materey [Maternal substitutes]. In V. V. Lebedinsky \& M. K. Bardyshevskaya (Eds.), Psykhologiya anomal'nogo razvitiya rebenka. Khrestomatiya [Psychology of abnormal child development. Reading book], 2, 39-54. Moscow: Moscow State University.

Hinde, R. (1975) Povedenye zhivotnykh [Animal behavior]. Moscow: Mir.

Klimas, D. G. (2008). Emotsional'naya regulatsiya u deteyi s rasstroyistvami autisticheskogo spectra [Emotional regulation in children with autistic spectrum disorders] (Unpublished doctoral thesis). Moscow: Moscow State University.

Kovalev, V. V. (1985). Semiotika i diagnostika psikhicheskykh zabolevaniyi [Semiotics and the assessment of mental disorders]. Moscow: Meditsina.

Lebedinsky, V. V. (2003) Narusheniya psikhicheskogo razvitiya $v$ detskom vozraste. [Disturbances of mental development in children]. Moscow: Academiya.

Lebedinsky, V. V., \& Bardyshevskaya, M. K. (2002). Affectivnoye razvitiye rebenka v norme i patologii [The affective development of a child, norm and pathology]. In V. V. Lebedinsky \& M. K. Bardyshevskaya (Eds.), Psykhologiya anomal'nogo razvitiya rebenka. Khrestomatiya [Psychology of abnormal child development. Reading book], 1, 588-681. Moscow: Moscow State University.

Lebedinsky, V. V., Nikolskaya, O. S., Bayenskaya, Ye. R., \& Libling, M. M. (1990). Emotsional'nyye narusheniya u deteyi. [Emotional disturbances in children.] Moscow: Moscow State University.

Malinovskyi, P. P. (2000). Tektologiya. Teoriya system. Teoreticheskaya biologiaya. [Tectology. The theory of systems. Theoretical biology.]. Moscow: Meditsina.

Mikhayilova, Yu. A. (2004). The development of emotional regulation in children under 4 years old reared in orphanages (Unpublished doctoral thesis). Moscow: Moscow State University.

Nikolskaya, O. S. (2000). Affectivnaya sphere cheloveka. [The affective sphere of people]. Moscow: Tsentr lechebnoy pedagogiki.

Segal, H. (1986). Delusion and artistic creativity \& other psychoanalytic essays. A Kleinian approach to clinical practice. London: Free Association Books.

Simonov, P. V. (1987). Motivitovannyi mozg [The motivating brain]. Moscow: Nauka.

Sukhareva, G. Ye. (1959). Lektsii po psikhiatrii detskogo voztasta [Lectures on child psychiatry], 2. Moscow: Medgiz.

Tinbergen, N., \& Tinbergen, E. (1983). Autistic children: New hope for a cure. London: George Allen \& Unwin.

Trevarthen, C. (2005). Action and emotion in the development of cultural intelligence: Why infants have feelings like ours. In J. Nadel \& D. Muir (Eds.), Emotional development, 61-91. Oxford: Oxford University Press.

Vallon, H. (1967). Psykhicheskoye razvitiye rebenka [The mental development of a child]. Moscow: Prosveshcheniye. 